\title{
Supporting Information for Integrating Tunable Anion Exchange with Reverse Osmosis for Enhanced Recovery During Inland Brackish Water Desalination
}

\author{
Ryan C. Smith and Arup K. SenGupta* \\ Department of Civil and Environmental Engineering, Lehigh University, Bethlehem, PA 18015, \\ USA \\ *Corresponding author, Email: arup.sengupta@lehigh.edu, Tel: (610) 758-3534
}

Number of Pages: 13

Number of Figures: 6

Number of Tables: 6 


\section{Section S1: Calculation of SI values for varying RO recovery}

Given a feedwater concentration, $C_{F}$, subjected to reverse osmosis the concentration of the concentrate, $C_{C}$, (assuming no loss of ions through the membrane) is given by the equation

$$
C_{C}=\frac{C_{F}}{1-R_{P}}
$$

Where $\mathrm{R}_{\mathrm{P}}$ is the recovery of the process. Figure 1 in the text was created by varying the recovery, $R_{P}$, from $10 \%$ to $90 \%$ and calculating the concentration of all ions in the concentrate solution. Then OLI Stream Analyzer Software was used to calculate the activity coefficients, and subsequently scaling potential, for $\mathrm{CaSO}_{4}$. 


\section{Section S2: Calculation of mixing ratio of ion exchange resins for any feedwater composition}

The continued operation of the Hybrid Ion Exchange-Reverse Osmosis (HIX-RO) process relies upon the fact that during the removal step, sulfate is selectively sorbed over chloride and during the regeneration step, chloride is selectively sorbed. During the removal step, sulfate is replaced by chloride by the following reaction

$$
2 \overline{\left(\mathrm{R}_{4} \mathrm{~N}^{+}\right) \mathrm{Cl}^{-}}+\mathrm{SO}_{4}^{2-} \rightarrow \overline{\left(\mathrm{R}_{4} \mathrm{~N}^{+}\right){ }_{2} \mathrm{SO}_{4}^{2-}}+2 \mathrm{Cl}^{-}
$$

Assuming ideality, the equilibrium constant, $K$, for an ion exchange reaction is known as the selectivity coefficient, and for the reaction between sulfate and chloride $K_{\mathrm{S} / \mathrm{Cl}}$ can be calculated by

$$
K_{\mathrm{S} / \mathrm{Cl}}=\frac{y_{\mathrm{S}} x_{\mathrm{Cl}}^{2}}{x_{\mathrm{S}} y_{\mathrm{Cl}}^{2}} \frac{C_{T}}{Q}
$$

Where $x$ is the fraction of sulfate or chloride in solution, $y$ is the fraction on the resin, $C_{T}$ is the total equivalent concentration of anions in meq/L, and $Q$ is the resin capacity in $\mathrm{meq} / \mathrm{g}$; subscripts $\mathrm{S}$ and $\mathrm{Cl}$ are sulfate and chloride, respectively. The value of $K_{\mathrm{S} / \mathrm{Cl}}$, however, does not provide insight as to whether sulfate or chloride is preferred. Instead, the separation factor, $\alpha_{\mathrm{S} / \mathrm{Cl} \text {, }}$ does and may be calculated from

$$
\alpha_{\mathrm{S} / \mathrm{Cl}}=\frac{y_{\mathrm{S}} x_{\mathrm{Cl}}}{x_{\mathrm{S}} y_{\mathrm{Cl}}}
$$

When $\alpha_{\mathrm{S} / \mathrm{Cl}}>1$, sulfate is the preferred species and vice versa. $\alpha_{\mathrm{S} / \mathrm{Cl}}$ is significantly different from $K_{\mathrm{S} / \mathrm{Cl}}$ and is not a constant. $\alpha_{\mathrm{S} / \mathrm{Cl}}$ will vary depending on solution concentration, $C_{T}$ and resin properties.

For the HIX-RO process, the ion exchange column must be properly designed to ensure that during the forward path of sulfate removal $\alpha_{\mathrm{S} / \mathrm{Cl}}>1$ and during the reverse path while using reject as chloride regeneration $\alpha_{\mathrm{S} / \mathrm{Cl}}<1$, and this is achieved by mixing together two different resins together in a desired ratio. The individual steps for solving for the proper mixing ratio are as follows:

1. Calculate $\alpha_{\mathrm{S} / \mathrm{Cl}}$ for both resins at feedwater and RO concentrate concentrations

2. Calculate the overall column separation factor $\alpha^{*} \mathrm{~s} / \mathrm{Cl}$

3. Determine the range of mixing ratios that ensures $\alpha^{*} \mathrm{~S} / \mathrm{Cl}>1$ at feedwater $C_{T}$ and $<1$ at RO concentrate $C_{T}$

$\underline{\text { Step 1: Calculate } \alpha_{\mathrm{S} / \mathrm{Cl}} \text { for both resins at feedwater and RO concentrate concentrations }}$

For a binary system where sulfate and chloride are the only anions present 


$$
x_{\mathrm{S}}+x_{\mathrm{Cl}}=1
$$

And

$$
y_{\mathrm{S}}+y_{\mathrm{Cl}}=1
$$

Equations 5 and 6 are rearranged and substituted into Equation 3 and rearranged to Equation 7 which can be solved for $y_{\mathrm{S}}$ for a given anion exchange resin (known $Q$ and $K_{\mathrm{S} / \mathrm{Cl}}$ values) and for a specific brackish water and reject stream (known $x_{\mathrm{S}}$ and $C_{T}$ for both streams).

$$
\frac{y_{\mathrm{S}}}{\left(1-y_{\mathrm{S}}\right)^{2}}=\frac{K Q x_{\mathrm{S}}}{\left(1-x_{\mathrm{S}}\right)^{2} C_{T}}
$$

Now that both $y_{\mathrm{S}}$ and $x_{\mathrm{S}}$ are known, $\alpha_{\mathrm{S} / \mathrm{C}}$ may be determined as follows

$$
\alpha_{\mathrm{S} / \mathrm{Cl}}=\frac{y_{\mathrm{S}}\left(1-x_{\mathrm{S}}\right)}{x_{\mathrm{S}}\left(1-y_{\mathrm{S}}\right)}
$$

$\underline{\text { Step 2: Calculate the overall column separation factor } \alpha^{*}} \underline{\mathrm{S} / \mathrm{Cl}}$

Considering a mixture of two different resins " $\mathrm{A}$ " and "B" with masses $m_{\mathrm{A}}$ and $m_{\mathrm{B}}$, the ratio of $\operatorname{resin} \mathrm{A}, \Phi_{\mathrm{A}}$, is

$$
\Phi_{A}=\frac{m_{A}}{m_{A}+m_{B}}
$$

Similarly for resin B

$$
\Phi_{B}=\frac{m_{B}}{m_{A}+m_{B}}=1-\Phi_{A}
$$

The total ion exchange capacity of the column is therefore

$$
Q^{*}=Q_{A} \Phi_{A}+Q_{B}\left(1-\Phi_{A}\right)
$$

And the overall column separation factor $\alpha^{*} \mathrm{~s} / \mathrm{Cl}$ may be calculated by

$$
\alpha_{\mathrm{S} / \mathrm{Cl}}^{*}=\frac{y_{\mathrm{S}}^{*} x_{\mathrm{Cl}}}{x_{\mathrm{S}} y_{\mathrm{Cl}}^{*}}
$$

Where 


$$
y_{S}^{*}=\frac{y_{S}^{A} Q_{A} \Phi_{A}+y_{S}^{B} Q_{B}\left(1-\Phi_{A}\right)}{Q^{*}}
$$

$y_{\mathrm{S}}$ for either resin is determined by solving Eq. 6 .

$\underline{\text { Step 3: Determine the range of mixing ratios that ensures } \alpha^{*} \underline{\mathrm{S} / \mathrm{Cl}}>1 \text { at feedwater } C_{T} \text { and }<1 \text { at }}$ $\underline{\mathrm{RO} \text { concentrate } C_{T}}$

The proper mixing ratio is determined by calculating $\alpha^{*} \mathrm{~S} / \mathrm{Cl}$ as $\Phi_{A}$ is varied from 0 to 1 at both influent and RO concentrate $C_{T}$ values. The range over which $\alpha{ }_{\mathrm{S} / \mathrm{Cl}}>1$ at influent $C_{T}$ and $\alpha{ }_{\mathrm{S} / \mathrm{Cl}}$ $<1$ at $\mathrm{RO}$ concentrate $C_{T}$ is the range of mixing ratios that will allow the HIX-RO process to operate.

Example with Actual Feedwater

Table S1 gives the composition of agricultural drainage water from the San Joaquin Valley

Table S1. Composition of San Joaquin Valley Agricultural Drainage Water

\begin{tabular}{l|c}
\multicolumn{1}{c|}{ Ion } & meq/L \\
\hline $\mathrm{Na}^{+}$ & 50.02 \\
$\mathrm{Mg}^{2+}$ & 4.99 \\
$\mathrm{Ca}^{2+}$ & 27.70 \\
$\mathrm{Cl}^{-}$ & 56.71 \\
$\mathrm{SO}_{4}{ }^{2-}$ & 21.24 \\
$\mathrm{HCO}_{3}{ }^{-}$ & 4.77 \\
\hline \multicolumn{1}{r}{$\mathbf{C}_{\mathbf{T}}$} & $\mathbf{8 2 . 7 2}$
\end{tabular}

The feedwater can be simplified by assuming all bicarbonate is converted to $\mathrm{Cl}^{-}$through dosing of $\mathrm{HCl}$ resulting in a feedwater that has approximately $60 \mathrm{meq} / \mathrm{L} \mathrm{Cl}^{-}$and $20 \mathrm{meq} / \mathrm{L} \mathrm{SO}_{4}{ }^{2-}$. The properties of polystyrene and polyacrylic resins can be found in open literature and are given in Table S2 ${ }^{1}$.

Table S2. Properties of polystyrene and polyacrylic resins

\begin{tabular}{c|c|c} 
& Polystyrene & Polyacrylic \\
\hline $\mathbf{K}$ & 35.00 & 663.4 \\
$\mathbf{Q}$ & 1.66 & 1.2
\end{tabular}

The feedwater $\mathrm{C}_{\mathrm{T}}$ is $80 \mathrm{meq} / \mathrm{L}$. If the desalination process is operated at $80 \%$ recovery, the $\mathrm{C}_{\mathrm{T}}$ of the RO concentrate would be $400 \mathrm{meq} / \mathrm{L}$. From Equations 6 and 7, $\alpha_{\mathrm{S} / \mathrm{Cl}}$ can be calculated at both $\mathrm{C}_{\mathrm{T}}$ values and is given in Table $\mathrm{S} 3$.

Table S3. Calculated values of $\alpha_{\mathrm{S} / \mathrm{Cl}}$ at feedwater and RO concentrate concentrations

$\begin{array}{rcc} & \text { Polystyrene } & \text { Polyacrylic } \\ \mathbf{8 0 ~} \mathbf{~ m e q} / \mathbf{L} & 0.771 & 4.985 \\ \mathbf{4 0 0} \mathbf{~ m e q} / \mathbf{L} & 0.183 & 1.695\end{array}$


Now, using equations 11 and $12, \alpha^{*} \mathrm{~s} / \mathrm{Cl}$ can be calculated over the range of mixing ratios and is shown in Figure S1.

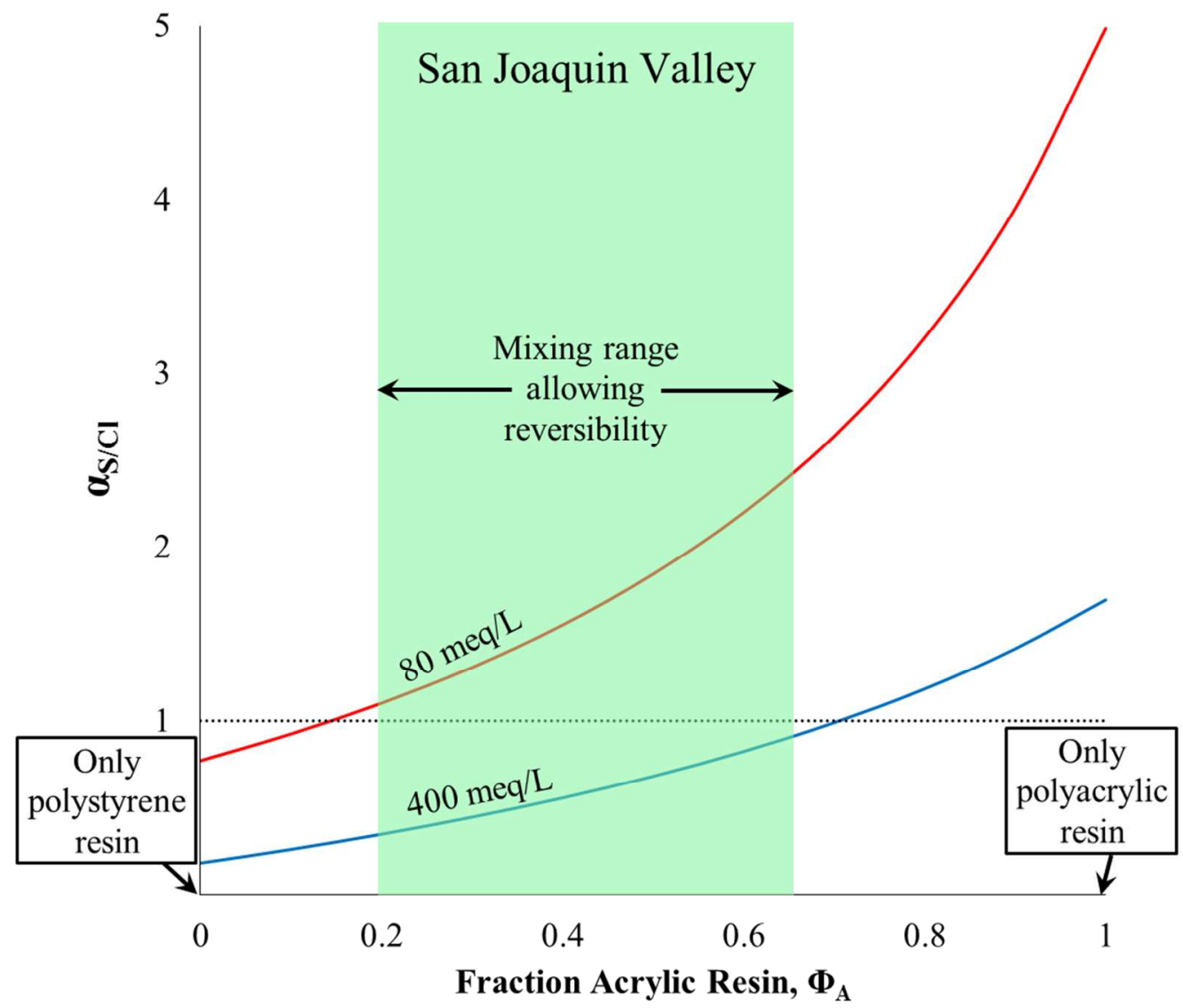

Figure S1. Variation in $\alpha^{*} \mathrm{~s} / \mathrm{Cl}$ with mixing ratio of polystyrene and polyacrylic resins

The shaded region from $\sim 0.2-0.7$ indicates the mixing ratio that will allow high process efficiency. 


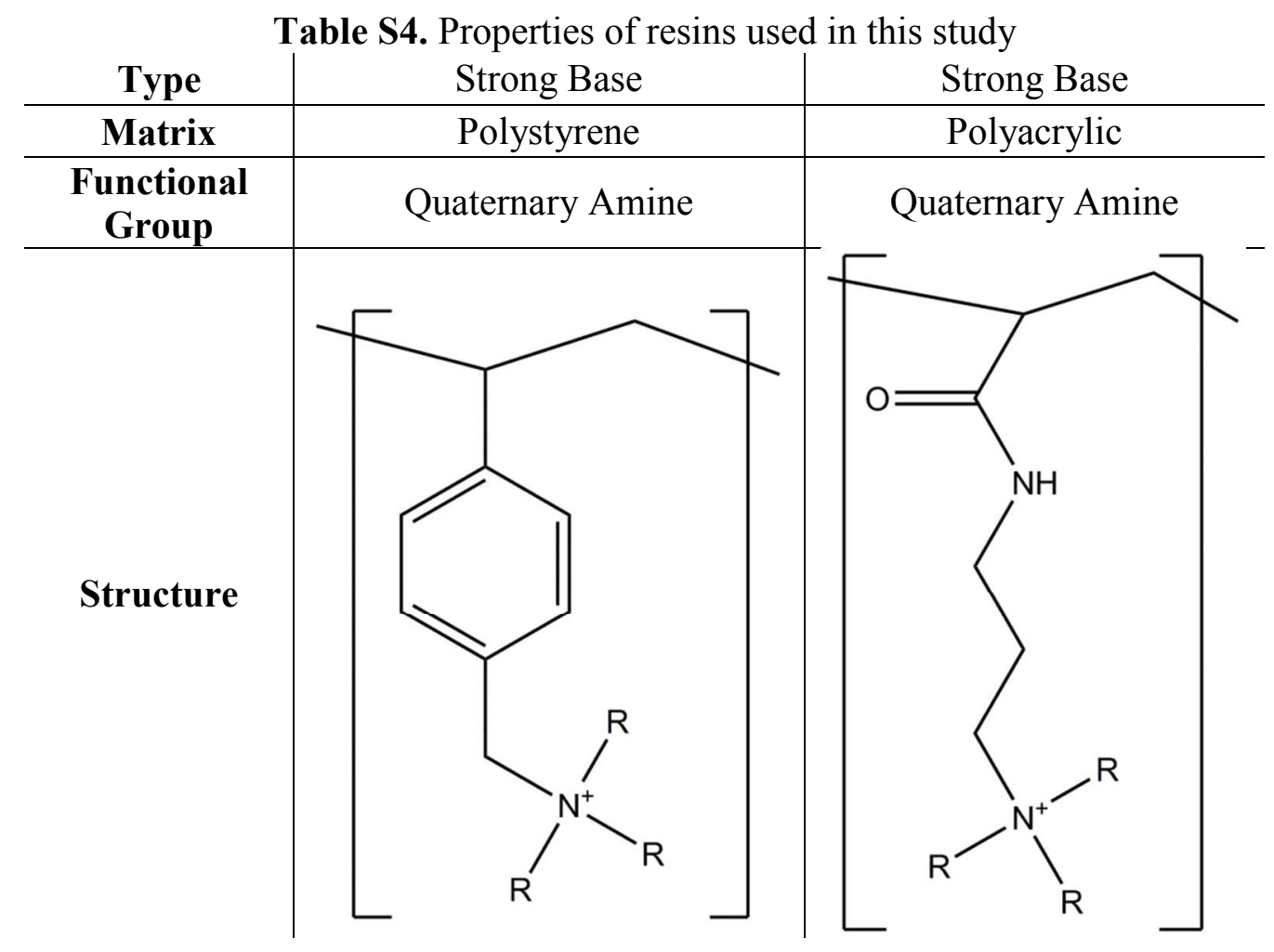




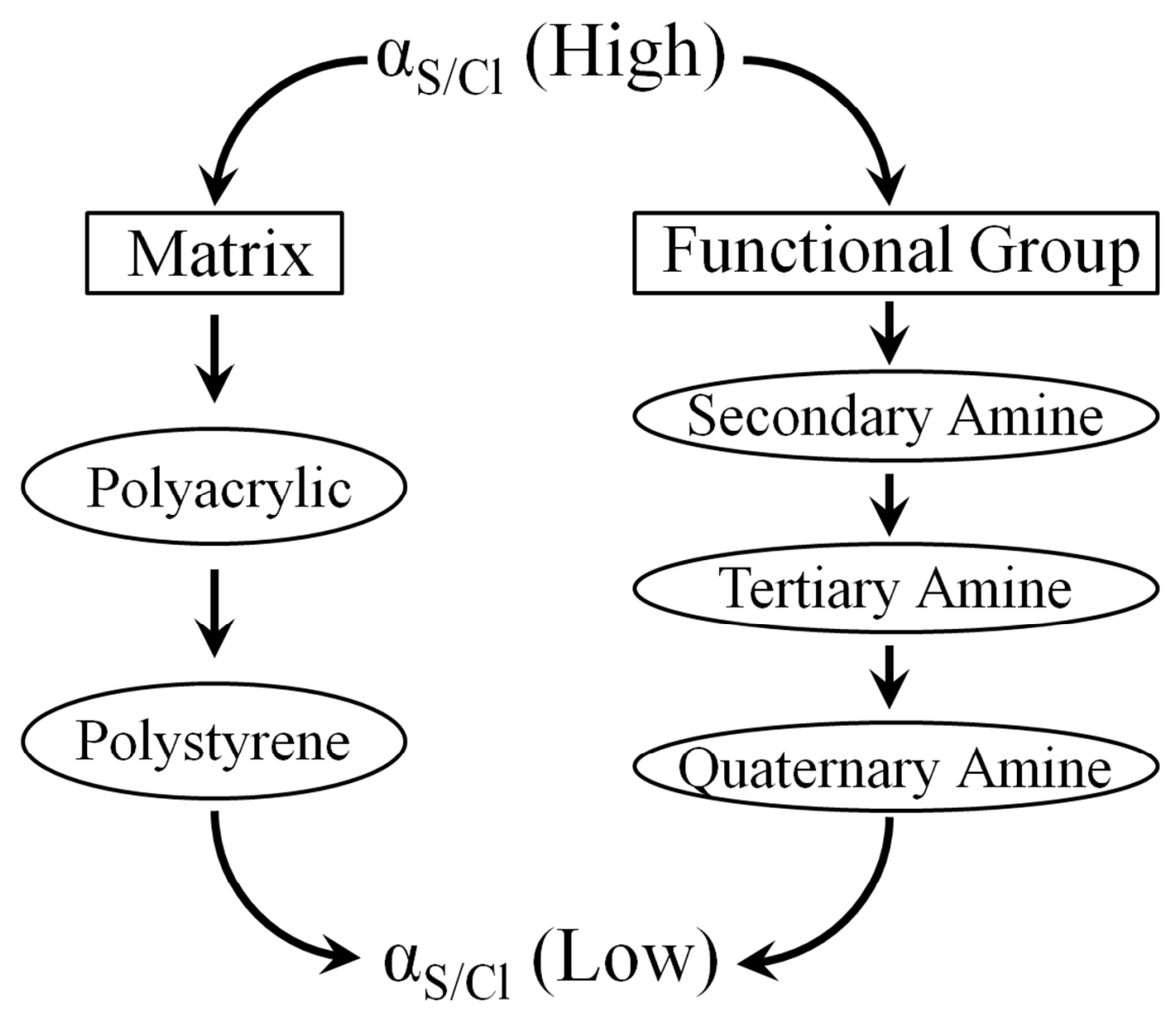

Figure S2. Controlling $\alpha_{\mathrm{S} / \mathrm{Cl}}$ by changing the either the matrix or functional group of the resin 


\section{Section S3: Characterization of RO system}

Flux and flow rates for each cycle are given for the 50/50 polyacrylic/polystyrene run, Table S5, and the pure polystyrene, Table S6. The Dow Filmtec SW30-2540 RO membrane has an effective membrane area of $2.8 \mathrm{~m}^{2}$.

Table S5. RO data for 50/50 polyacrylic/polystyrene run

\begin{tabular}{c|c|c|c|c|c} 
Cycle & $\begin{array}{c}\text { Permeate } \\
\text { Flux } \\
\left(\mathrm{L} / \mathrm{m}^{2}-\mathrm{hr}\right)\end{array}$ & $\begin{array}{c}\text { Permeate } \\
\text { Flow Rate } \\
(\mathrm{L} / \mathrm{min})\end{array}$ & $\begin{array}{c}\text { Concentrate Flow } \\
\text { Rate } \\
(\mathrm{L} / \mathrm{min})\end{array}$ & $\begin{array}{c}\text { Total Flow } \\
\text { Rate } \\
(\mathrm{L} / \mathrm{min})\end{array}$ & $\begin{array}{c}\text { Percent } \\
\text { Recovery }\end{array}$ \\
\hline 1 & 46.0 & 2.15 & 0.59 & 2.74 & $78.5 \%$ \\
2 & 43.6 & 2.03 & 0.44 & 2.48 & $82.1 \%$ \\
3 & 46.7 & 2.18 & 0.56 & 2.74 & $79.7 \%$ \\
4 & 44.7 & 2.09 & 0.58 & 2.66 & $78.4 \%$ \\
5 & 42.1 & 1.96 & 0.57 & 2.54 & $77.5 \%$ \\
6 & 44.4 & 2.07 & 0.56 & 2.63 & $78.8 \%$ \\
7 & 41.7 & 1.95 & 0.60 & 2.55 & $76.4 \%$ \\
8 & 42.7 & 2.00 & 0.64 & 2.63 & $75.8 \%$ \\
9 & 44.5 & 2.08 & 0.51 & 2.59 & $80.2 \%$ \\
10 & 40.4 & 1.88 & 0.48 & 2.36 & $79.7 \%$
\end{tabular}

Table S6. RO data for pure polystyrene run

\begin{tabular}{c|c|c|c|c|c} 
Cycle & $\begin{array}{c}\text { Permeate } \\
\text { Flux } \\
\left(\mathrm{L} / \mathrm{m}^{2}-\mathrm{hr}\right)\end{array}$ & $\begin{array}{c}\text { Permeate } \\
\text { Flow Rate } \\
(\mathrm{L} / \mathrm{min})\end{array}$ & $\begin{array}{c}\text { Concentrate Flow } \\
\text { Rate } \\
(\mathrm{L} / \mathrm{min})\end{array}$ & $\begin{array}{c}\text { Total Flow } \\
\text { Rate } \\
(\mathrm{L} / \mathrm{min})\end{array}$ & $\begin{array}{c}\text { Percent } \\
\text { Recovery }\end{array}$ \\
\hline 1 & 39.1 & 1.82 & 0.41 & 2.24 & $81.6 \%$ \\
2 & 38.1 & 1.78 & 0.45 & 2.23 & $79.8 \%$ \\
3 & 35.3 & 1.65 & 0.38 & 2.02 & $81.4 \%$ \\
4 & 36.9 & 1.72 & 0.45 & 2.17 & $79.2 \%$ \\
5 & 36.6 & 1.71 & 0.42 & 2.13 & $80.3 \%$ \\
6 & 33.1 & 1.54 & 0.33 & 1.87 & $82.4 \%$ \\
7 & 35.8 & 1.67 & 0.43 & 2.10 & $79.5 \%$ \\
8 & 37.1 & 1.73 & 0.45 & 2.18 & $79.3 \%$ \\
9 & 33.4 & 1.56 & 0.35 & 1.91 & $81.7 \%$ \\
10 & 32.7 & 1.53 & 0.39 & 1.92 & $79.5 \%$
\end{tabular}




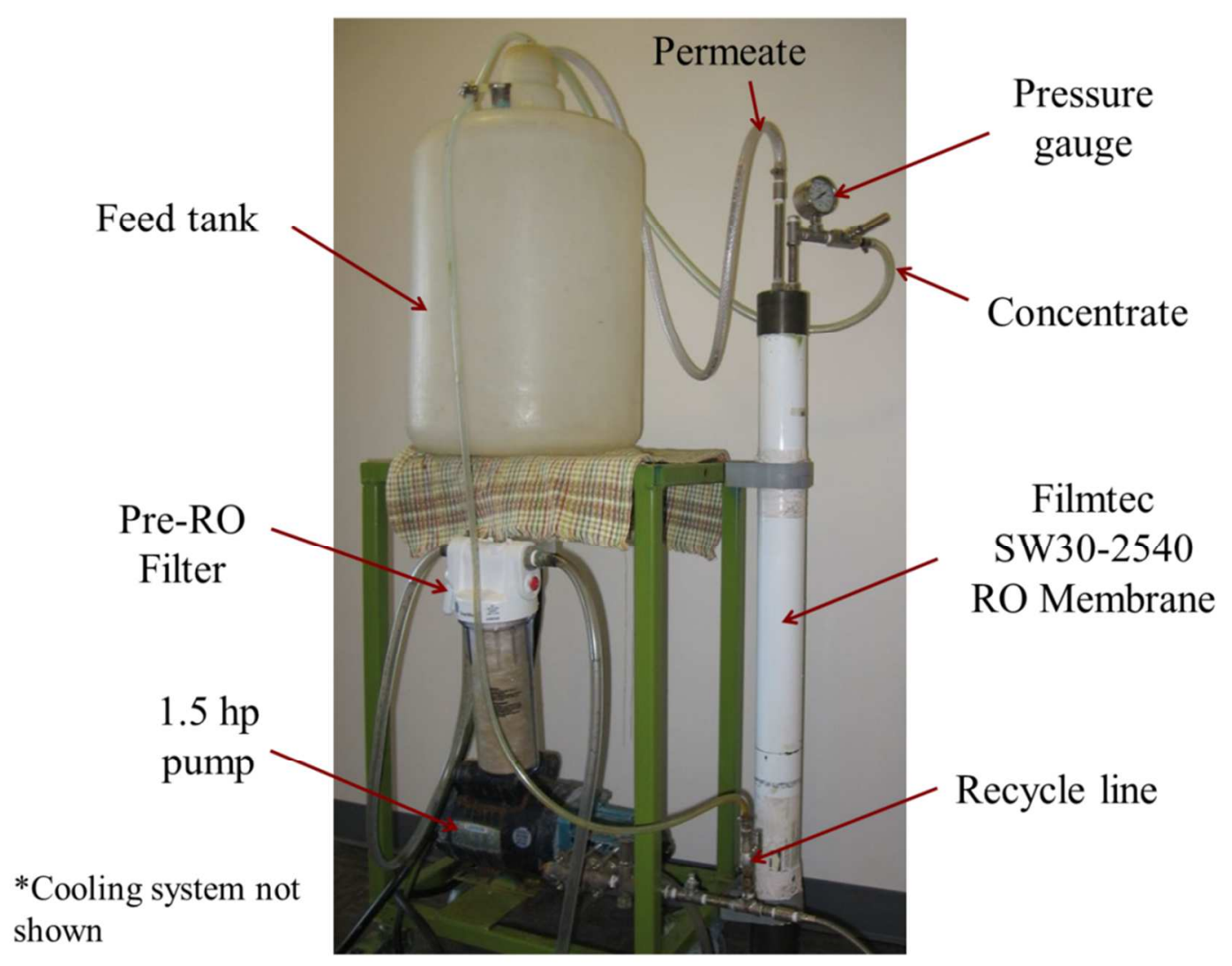

Figure S3. Setup for Reverse Osmosis 


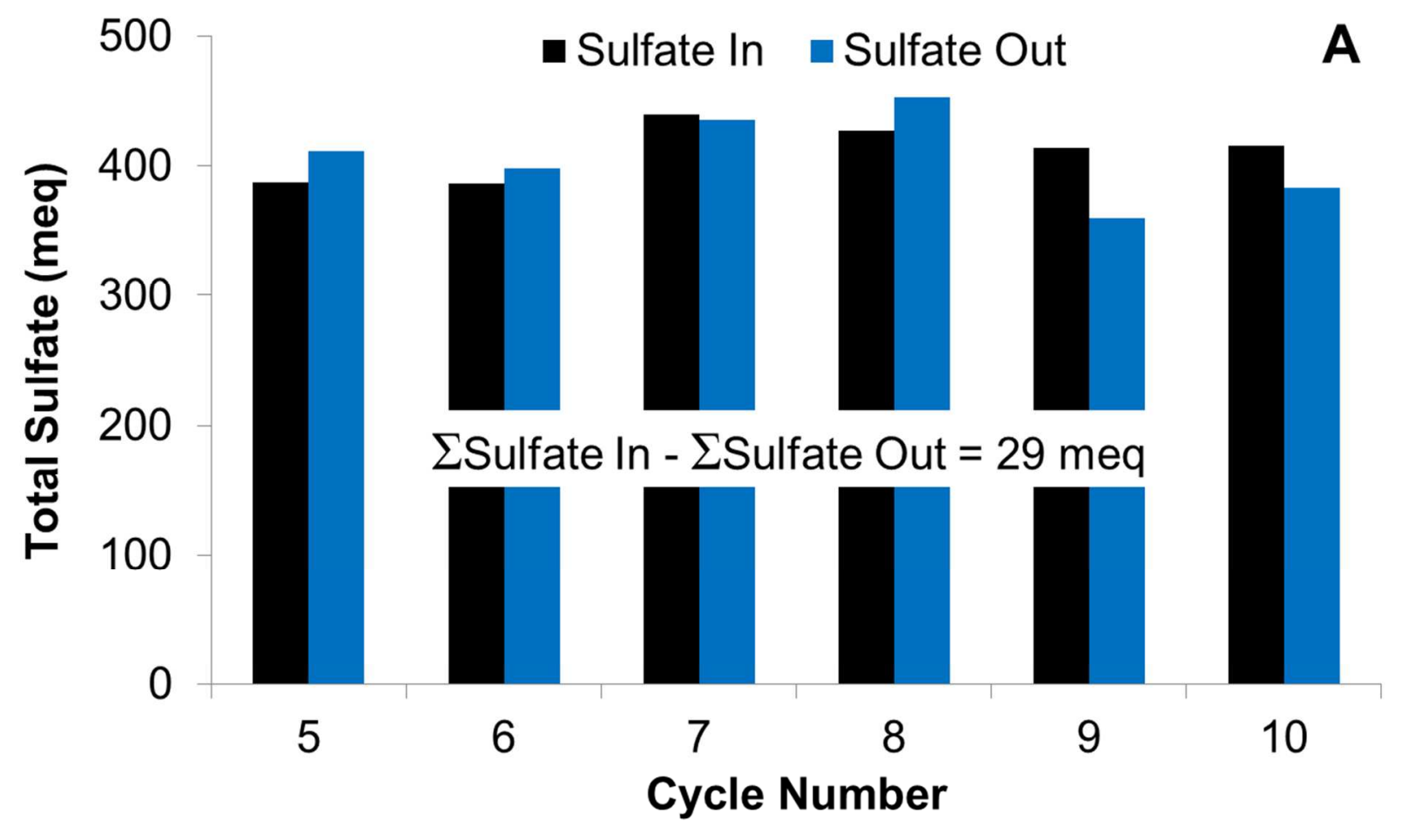

- Sulfate In $\quad$ Sulfate Out B

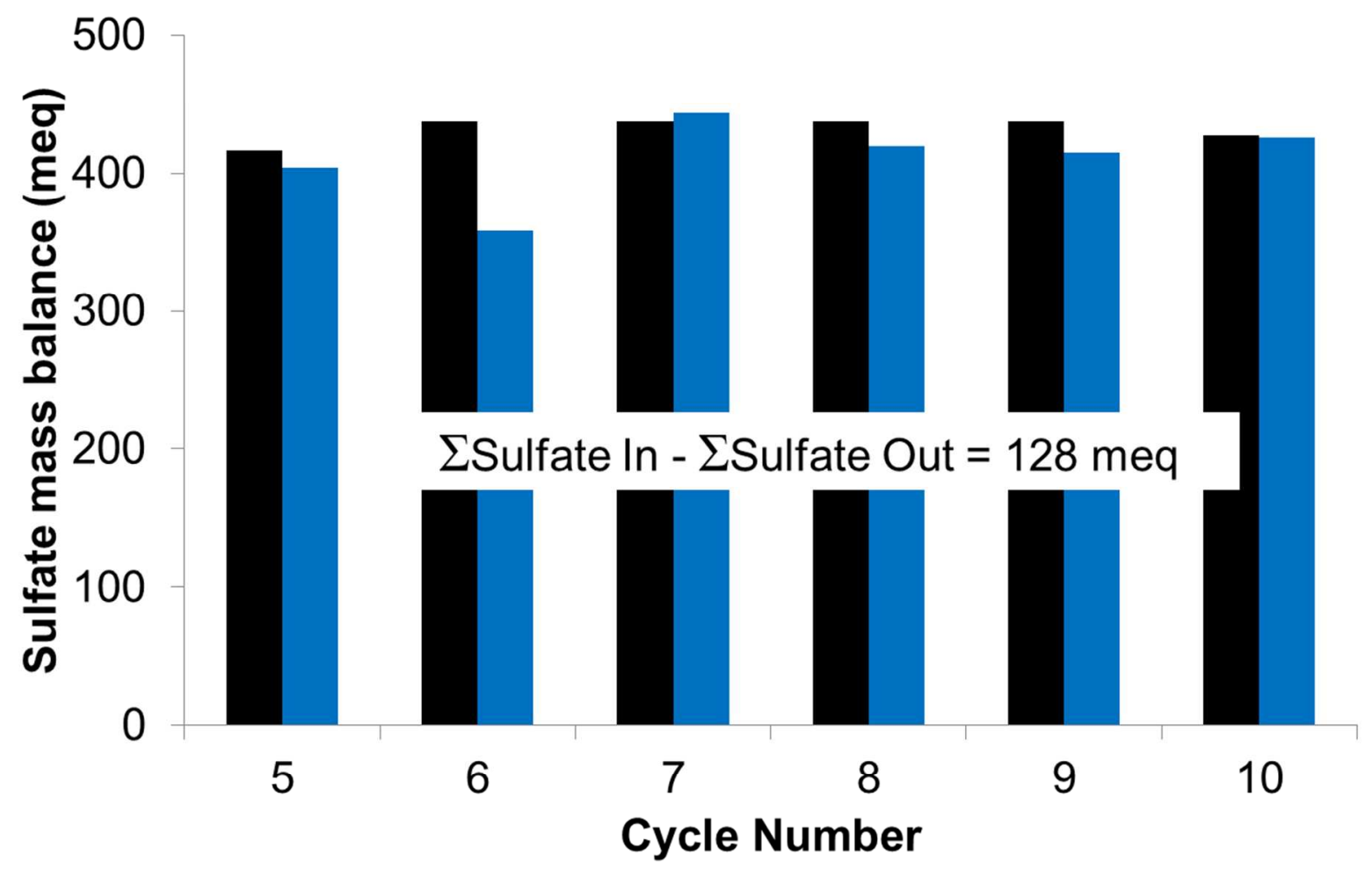

Figure S4. (A) Sulfate mass balance for mixed bed system (B) Sulfate mass balance for polystyrene bed 


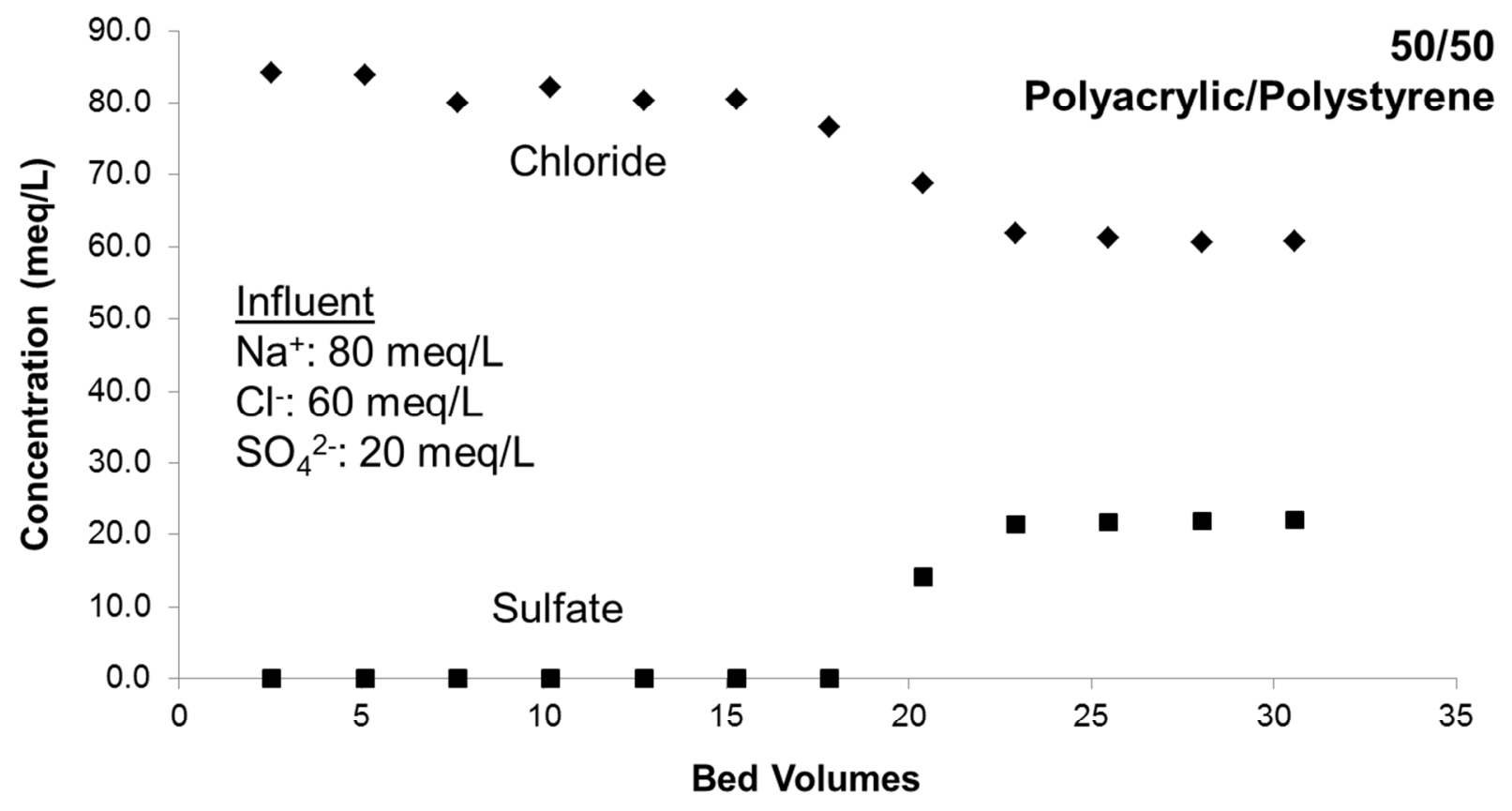

Figure S5. Breakthrough curve for 50/50 polystyrene/polyacrylic column 


\section{Section S4: In-column precipitation procedure}

The procedure for studying the potential for in-column precipitation is detailed in Figure S6.

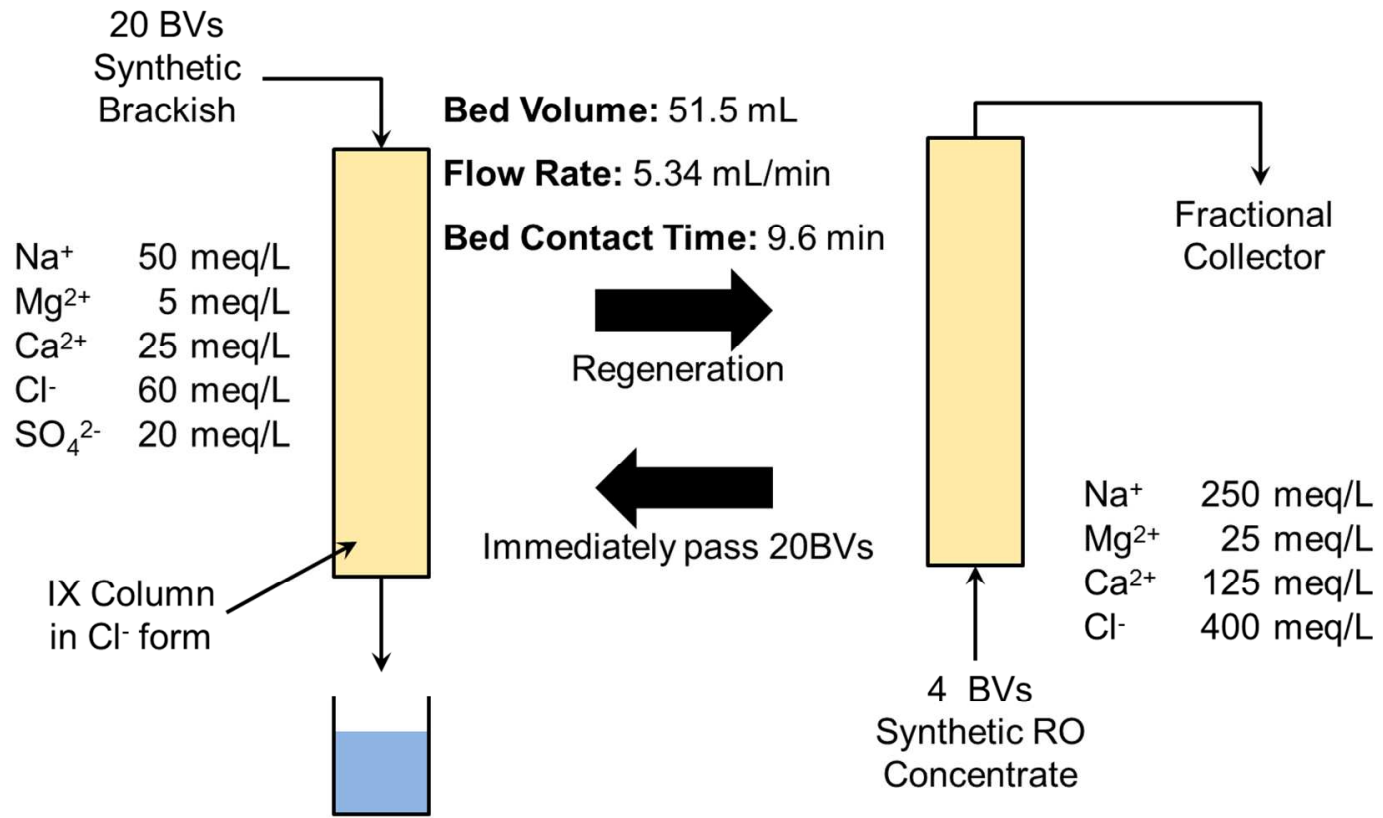

Figure S6. Procedure for measuring potential for precipitation of $\mathrm{CaSO}_{4}$ in the ion exchange column

To begin, the ion exchange column is placed in chloride form by passing a dilute $\mathrm{NaCl}$ solution until the column is completely in $\mathrm{Cl}^{-}$form. The column is then washed with DI water until no chloride is detected in the effluent. The influent solution is the same as the feedwater except all bicarbonate is replaced by chloride. Then, like the large scale system, $20 \mathrm{BVs}$ of solution are passed and collected. Synthetic regenerant is used that is 5 times the concentration of the feedwater but all the sulfate has been replaced by chloride. 4BVs of regenerant is then passed upflow through the column and collected in a fractional collector.

\section{REFERENCES}

(1) Clifford, D.; Weber Jr., W.J. The determinants of divalent/monovalent selectivity in anion exchangers. React. Polym. 1983, 1, 77-89. 